\title{
Nystagmus intensity and direction in bow and lean test: an aid to diagnosis of lateral semicircular canal benign paroxysmal positional vertigo
}

\author{
Intensità e direzione del nistagmo nel "bow and lean test": un contributo \\ alla diagnosi nella vertigine parossistica da posizionamento benigna del canale \\ semicircolare laterale \\ V. MARCELLI \\ Department of Neuroscience, Vestibular and Audiology Unit, University of Naples "Federico II”, Naples, Italy. \\ Vestibular and Audiology Unit; ASL NA-1, San Giovanni Bosco Hospital, Naples, Italy
}

\begin{abstract}
SUMMARY
The objective was to evaluate nystagmus intensity and direction (NID) during bow and lean test (BLT) in subjects suffering from idiopathic lateral semicircular canal benign paroxysmal positional vertigo (LSC-BPPV), in order to differentiate between the geotropic and the apogeotropic form and to determine the affected ear before using classic diagnostic procedures. The BLT was performed in 32 subjects affected by LSC-BPPV. "Nystagmus intensity" evaluation allows distinguishing the geotropic variant from the apogeotropic one, while the "nystagmus direction" allows identification of the side. In particular, a more intense nystagmus in the bow position compared to the lean position indicates an ampullipetal flow caused by the presence of free-floating particles in the non-ampullary arm, and is suggestive of geotropic form. In this case, if the nystagmus in the bow position is left beating, the free-floating particles necessarily occupy the left LSC non-ampullary arm, while a right-beating nystagmus indicates the right LSC involvement. In contrast, a more intense nystagmus in the lean position compared to the bow position indicates an ampullifugal flow due to the presence of particles adherent to the cupula (cupulolithiasis) or free-floating in the ampullary arm (canalolithiasis), suggesting an apogeotropic form. In this situation, if the nystagmus in the lean position is left beating, the particles are in the left LSC ampullar arm or are coated on the left LSC cupula; vice versa, a right-beating nystagmus in the lean position is suggestive of the involvement of the right LSC. As a general rule, in both forms the direction of the more intense nystagmus points to the affected side. "NID-BLT" was effective in identifying the form and the side in $22 / 28$ subjects (79\% of the study population). The proper execution and interpretation of the "NID-BLT" helps to establish the form (geotropic versus apogeotropic) and side (right versus left) in most cases of LSC-BPPV. Unlike Choung's test, which requires knowing a priori if the form is geotropic or apogeotropic, our test enables fast and accurate diagnosis, or at least provides indispensable elements if the diagnosis of the affected side is doubtful, with the patient remaining in the sitting position.
\end{abstract}

KEY WORDS: Benign paroxysmal positional vertigo $\bullet$ Lateral semicircular canal $\bullet$ Vestibular system $\bullet$ Nystagmus

\section{RIASSUNTO}

L'obiettivo è stato valutare bed side l'intensità e la direzione del nistagmo (NID) nelle due differenti posizioni del "bow and lean test" (BLT) per differenziare la forma geotropa dalla forma apogeotropa e determinare il lato affetto in caso di vertigine parossistica da posizionamento benigna idiopatica da litiasi a carico del canale semicircolare laterale (LSC-BPPV), prima ancora di utilizzare le classiche manovre diagnostiche. Sono stati esaminati 32 soggetti affetti da LSC-BPPV, in ognuno dei quali sono state valutate l'intensità e la direzione del nistagmo nelle due posizioni del BLT. L'intensità del nistagmo consente di differenziare la forma geotropa della forma apogeotropa mentre la direzione del nistagmo consente di indentificare il lato affetto. Per le noti legge che governano la fisiopatologia del CSL, un nistagmo più intenso in flessione del capo (bow) rispetto all'estensione (lean) indica un flusso ampullipeto e quindi la presenza di materiale flottante nel braccio non ampollare, tipico della forma geotropa. In tal caso, se il nistagmo in flessione (bow) è diretto a sinistra, il materiale flottante deve necessariamente occupare il braccio non ampollare del CSL sinistro; viceversa se il nistagmo in flessione è diretto a destra. D'altro canto, un nistagmo più intenso in estensione del capo (lean) rispetto alla flessione (bow) indica un flusso ampullifugo e quindi la presenza di materiale aderente alla cupola (cupololitiasi) o flottante nel braccio ampollare (canalolitiasi), tipico della forma apogeotropa. In tal caso, se il nistagmo in estensione (lean) è diretto a sinistra, il materiale flottante deve necessariamente occupare il braccio ampollare del CSL sinistro; viceversa se il nistagmo in estensione è diretto a destra. Come regola generale, in entrambe le forme la direzione del nistagmo con maggiore intensità indica il lato affetto. Il "NID-BLT" è risultato efficace nell'identificare la forma ed il lato affetto in ventidue soggetti su ventotto (79\% del campione). In caso di LSC-BPPV, la corretta esecuzione ed interpretazione del "NID-BLT" fornisce un importante aiuto nello stabilire la forma (geotropa versus apogeotropa) e la sede (destra versus sinistra) nella maggior parte dei pazienti, prima ancora di utilizzare le classiche manovre diagnostiche. A differenza del test di Choung, che richiede di conoscere a priori se il paziente ha una forma geotropa o apogeotropa, il nostro test consente di formulare direttamente la diagnosi o di fornire elementi indispensabili nei casi in cui la diagnosi di lato è dubbia, mentre il paziente è ancora in posizione seduta.

PAROLE CHIAVE: Vertigine parossistica da posizionamentobenigna $\bullet$ Canale semicircolare laterale $\bullet$ Nistagmo

Acta Otorhinolaryngol Ital 2016;36:520-526 


\section{Introduction}

Lateral semicircular canal benign paroxysmal positional vertigo (BPPV) results from the movement of dense particles in the lateral semicircular canal (LSC). The diagnostic test is the supine roll test, also called Pagnini-McClure manoeuver ${ }^{12}$, showing in the two positions a typical horizontal, paroxysmal bipositional bidirectional nystagmus which is apogeotropic in case of dense particles adherent to the cupula (cupulolithiasis) or free-floating in the LSC ampullary arm and geotropic in case of dense particles freefloating in the LSC non-ampullary arm (canalolithiasis) ${ }^{3-5}$. Indeed, the identification of the affected ear is fundamental, in order to perform the right repositioning manoeuvre.

In the apogeotropic form, the nystagmus is more intense when the affected ear is up, since this position provokes a direct (cupulolithiasis) or indirect (canalolithiasis, endolymph-mediated) excitatory deflection of the cupula, according to Ewald's $2^{\text {nd }}$ law. Conversely, when the affected ear is down, the nystagmus is less intense since this position provokes an inhibitory deflection of the cupula, again according to Ewald's $2^{\text {nd }}$ law. In contrast, the geotropic form is characterised by a nystagmus that is more intense when the affected ear is down, since this position provokes an indirect, endolymph-mediated excitatory deflection of the cupula, while the nystagmus is less intense with the affected ear up, since this position provokes an indirect, endolymph-mediated inhibitory deflection of the cupula. As a result, the affected ear can be determined as the side showing the more intense nystagmus in the geotropic form and the side showing the less intense nystagmus in the apogeotropic form ${ }^{46}$.

However, it is sometimes difficult to identify the differences in nystagmus intensity, and consequently several tests for secondary signs of lateralisation, performed both in erect and supine position, have been described: "pseudo-spontaneous" nystagmus ${ }^{67}$, "null-point" in the pitch plane ${ }^{78}$, "bending nystagmus" ", "bowing and leaning Choung's test" ${ }^{10}$, "head shaking test-induced nystagmus" (HSIN) ${ }^{7}$, sitting to supine position tests ${ }^{11-14}$, null point in supine position ${ }^{15} 16$.

However, these manoeuvre are often not well tolerated by the patient and are not always sufficient to identify the affected side. To reduce the discomfort to the patient and facilitate diagnosis, we have modified the execution and interpretation of Choung's test ${ }^{10}$, developing a new method, called "nystagmus intensity and direction" bow and lean test (NID-BLT), which consists in the evaluation of different nystagmus directions, as in the original Choung's test ${ }^{10}$, along with comparison of the different nystagmus intensity in the two positions.

\section{Materials and methods}

One hundred and six subjects with a history of recent, first and idiopathic episode of BPPV without any other associ- ated labyrinthine disease were recruited from September to November 2015 and underwent vestibular examination using an infrared video-nystagmoscopic and video-nystagmographic instrument (VNG Ulmer; Synapsys S.A., Marseille, France) without fixation, according to the following procedure, designed to identify the subgroup with LSC-BPPV on which to evaluate the accuracy of NIDBLT.

Step 1: the patient, seated with the head in axis with the trunk (starting position), is assessed for a horizontal pseudo-spontaneous nystagmus or for a horizontal nystagmus induced by gentle lateral head rotations to either side. Such a horizontal nystagmus, which may be present in subjects suffering from LSC-BPPV, when present, is generated by the slow slide of the dense particles along the LSC. Since the LSC is anteriorly inclined by $30^{\circ}$ forward relative to the horizontal plane, it behaves as a natural and true inclined plane along which the dense particles slowly slide, resulting in either an excitatory (dense particles adherent to the cupula or free-floating in the ampullary arm) or inhibitory (dense particles in non-ampullary arm) deflection of the cupula and nystagmus (Fig. 1).

Step 2: Choung's bow and lean test (BLT)10 is performed. As described by Choung et al. ${ }^{10}$, the nystagmus direction reversal has been assessed, first when the patient bowed forward the head over $90^{\circ}$ ("bowing nystagmus") and then leaned the head backward over $45^{\circ}$ ("leaning nystagmus") in the sitting position. The nystagmus direction reversal, which occurs in most cases, is determined by the fact that, in the two different positions, the LSC plane radically reverses its inclination relative to the horizontal plane, thus causing an opposite sliding direction of the dense particles in the two positions.

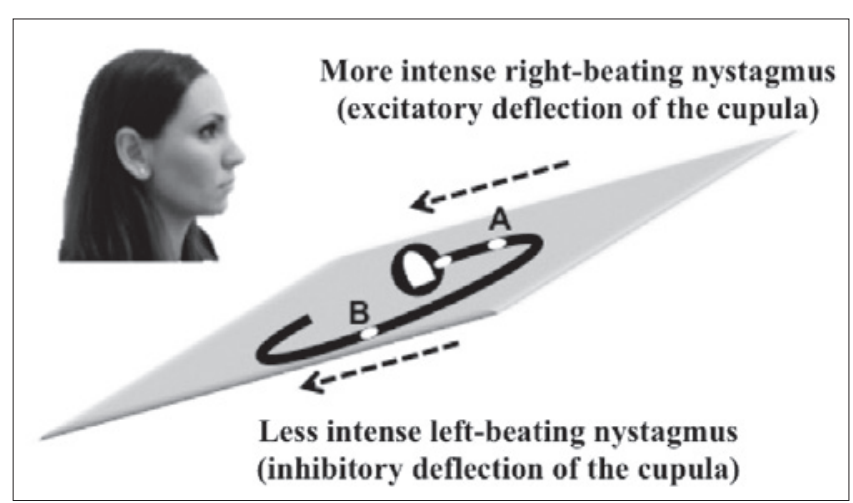

Fig. 1. The figure shows a right LSC-BPPV. In the patient seated with the head in axis with the trunk, the dense particles slide posteriorly and determine an excitatory (white dense particles adherent to the cupula or free-floating in the ampullary arm - A) or inhibitory (white dense particles in the non-ampullary arm - B) deflection of the cupula. The result is a horizontal pseudospontaneous nystagmus or a horizontal nystagmus induced by a gentle head rotation. Black arrows show ampullipetal and ampullifugal flow, respectively. Cupula, white. 
In patients in which the presence of LSC-BPPV has been hypothesised, the NID-BLT was performed as follows. First, the so-called "null point" was sought. The "null point" is the point of forward head tilt where the pseudospontaneous nystagmus or nystagmus generated by head rotation/BLT disappears: when the LSC lies on a horizontal plane, in fact, the spontaneous sliding of the particles disappears and so does the nystagmus (Fig. 2).

This preliminary phase is the first precondition for proper execution and interpretation of the test: by comparing the nystagmus intensity in the two BLT positions, only if the magnitude of the LSC tilt is identical in the two opposite positions can we be certain that the dense particles run through the affected LSC at the same speed and that the difference in nystagmus intensity is solely due to the Ewald's $2^{\text {nd }}$ law. Once the null point is identified, which is slightly different in each subject due to the inevitable anatomical differences, we bow the head of $30^{\circ}$ with respect to the null point itself and wait for about 30 seconds.

The next phase is the proper NID-BLT test: the head is leant $60^{\circ}$ backward, and the nystagmus is evaluated; about 30 seconds later, the head is bowed $60^{\circ}$ forward and the nystagmus intensity assessed again. This is the second, indispensable requisite to be followed when doing the NID-BLT. In fact, it would be a mistake just comparing the nystagmus generated by a forward head tilt of $30^{\circ}$ from the null point (bow) with the one generated by a $60^{\circ}$ backward head tilt (lean). Yet, the same principle is to be respected in the execution of the Pagnini-McClure manoeuvre when it is crucial to compare the nystagmus intensity generated by a $90^{\circ}$ head rotation from right to left and vice versa and not by comparing the nystagmus generated by a head rotation from the supine to side $\left(45^{\circ}\right)$ with the nystagmus generated by a head rotation to the opposite side ${ }^{19}\left(90^{\circ}\right)$.

In order to assess the degree of operator dependence and the accuracy of the bed-side examination, two physicians were involved in the evaluation of the test results. The au-

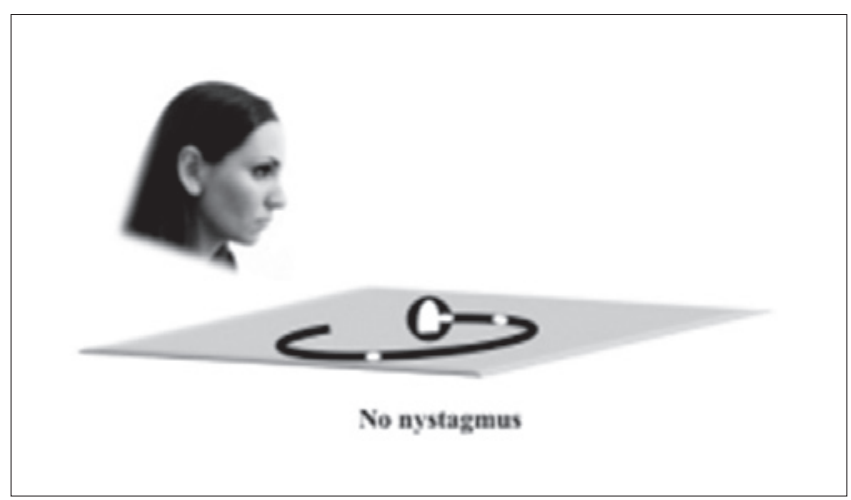

Fig. 2. When the LSC is no longer inclined relative to the horizontal plane, but parallel to it due to forward tilt of the head, the spontaneous sliding of the particles (white ovals) and the (pseudo-) spontaneous nystagmus disappears. thor evaluated bedside the nystagmus intensity and direction while another skilled physician analysed the videonystagmographic recordings.

The different "nystagmus intensity" in the bow and in the lean positions was used to differentiate a geotropic form from an apogeotropic one and was evaluated as follows. After locating the null point, a more intense nystagmus in the bow position (head $30^{\circ}$ forward) compared to the lean position (head $30^{\circ}$ backward) is indicative of an ampullipetal, excitatory deflection of the cupula (according to Ewald's 2nd law). Consequently, more intense nystagmus must necessarily be generated by free-floating particles present in the LSC non-ampullar army, and this finding is suggestive of a geotropic form (Fig. 3).

Similarly, a more intense nystagmus in the lean position compared to the bow position is again indicative of an ampullipetal, excitatory deflection of the cupula. Consequently, more intense nystagmus must be necessarily generated by particles adherent to the cupula (cupulolithiasis) or by free-floating particles present in the LSC ampullary arm (canalolithiasis), and this finding is suggestive of an apogeotropic form.

"Direction nystagmus" evaluation allows identification of the affected side when associated with the "intensity nystagmus" evaluation. As already discussed, a nystagmus that is more intense in the bow position than in the lean position indicates the presence of free-floating particles in LSC non-ampullary arm, therefore suggestive of a geotropic form. Now, if the nystagmus in the bow position is left-beating, the free-floating particles must necessarily occupy the left LSC non-ampullary arm; in a similar way, if the nystagmus in the bow position is right-beating, the free-floating particles must necessarily occupy the right LSC non-ampullary arm (Fig. 3).

On the other hand, a more intense nystagmus in the lean position compared to the bow position indicates the presence of particles adherent to the cupula (cupulolithiasis) or free-floating in the ampullary arm (canalolithiasis), typical of an apogeotropic form. In such cases, if the nystagmus in the lean position is left beating, the particles are necessarily either in the left LSC ampullary arm or coated on the left LSC cupula; if the nystagmus in the lean position is right-beating, the particles occupy either the right LSC ampullary arm or are coated on the right LSC cupula (Fig. 4). We tested the accuracy index (AUC) of the modified BLT with SPSS software version 20 (IBM SPSS), which allowed us to depict ROC curve.

\section{Results}

Among the 106 subjects, 22 showed a pseudo-spontaneous nystagmus and 6 showed a horizontal nystagmus that appeared after lateral head rotations to either side, while 78 patients did not show any kind of horizontal nystagmus. These data strongly suggest the presence of LSC- 


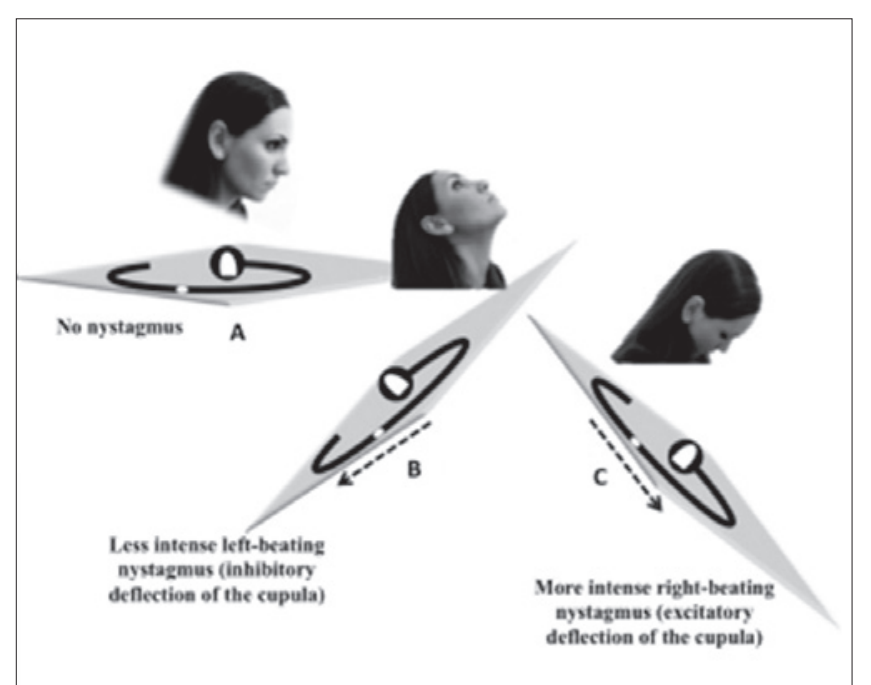

Fig. 3. In the "null point" position (A), the spontaneous sliding of the particles (white oval) and the (pseudo-) spontaneous nystagmus disappear. In the lean backward position (B), the particles slide posteriorly and demonstrate an ampullifugal inhibitory flow (black arrow) responsible for a left beating nystagmus. In the bow forward position (C), the particles slide anteriorly and demonstrate an ampullipetal excitatory flow (black arrow) responsible for a more intense right beating nystagmus. As a general rule, a more intense nystagmus in the bow position indicates a geotropic form (dense particles free floating in non-ampullary arm, canalolithiasis) and in this position the nystagmus direction indicates the affected side.

BPPV in 28/106 subjects (16 females, 12 males; mean age $45.96+/-5.45$ years; duration of symptoms on average $11.57+/-4.18$ days). Among these 28 subjects, the BLT reversed nystagmus direction in $24 / 28$, while the direction of the nystagmus was not modified in $4 / 28$ patients; these 4 patients (three females, one male; mean age $53.50+/-11.73$ years; duration of symptoms on average $27.00+/-3.56$ days) were excluded from the study. Among the remaining 78 subjects who did not show any nystagmus in the starting position, the BLT generated a horizontal nystagmus that reversed direction in the two positions in 4/78 subjects; in these four additional subjects the presence of LSC-BPPV was strongly hypothesised.

Overall, in 32 subjects we hypothesised the presence of LSC-BPPV.

In 28 out of 32 subjects, the "NID-BLT" results made us assume the presence of 22 geotropic forms (14 right-sided, 8 left-sided), and 6 apogeotropic forms, (4 right-sided, 2 left-sided). The Pagnini-McClure manoeuver confirmed the NID-BLT findings in 18/22 geotropic forms (82\% of the sample) and in $4 / 6$ apogeotropic forms (67\% of the sample).

Overall, the "NID-BLT" proved effective in identifying the form and the side in $22 / 28$ subjects $(79 \%$ of the sample). All subjects affected by geotropic form were subjected to the liberatory Gufoni manoeuver, which was

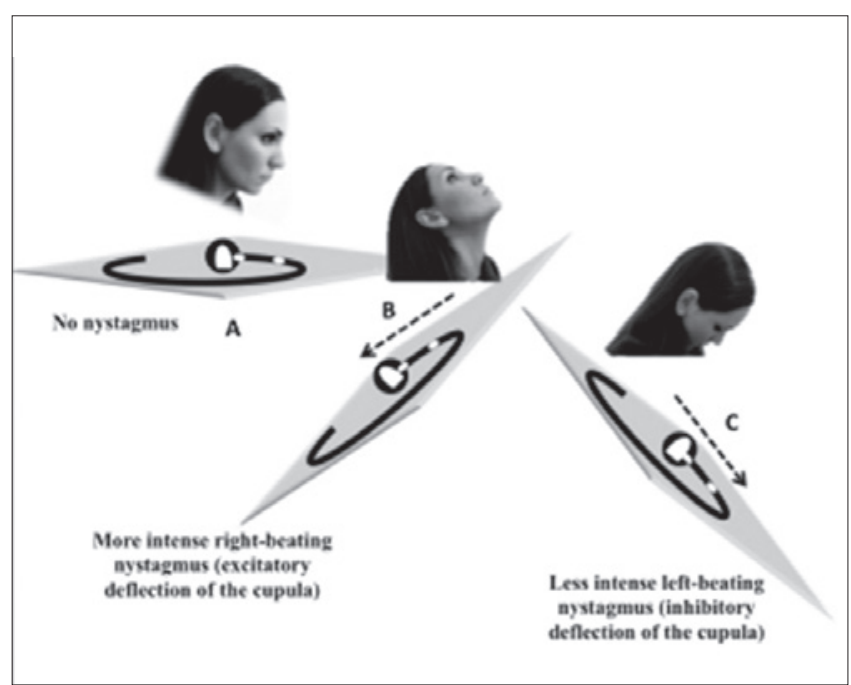

Fig. 4. In the "null point" position (A), the spontaneous sliding of the particles (white oval) and the (pseudo-) spontaneous nystagmus disappear. In the lean backward position (B), the particles slide posteriorly and demonstrate an ampullipetal excitatory flow (black arrow) responsible for a right beating nystagmus. In the bow, forward position (C), the particles slide anteriorly and demonstrate an ampullifugal inhibitory flow (black arrow) responsible for a less intense left beating nystagmus. As a general rule, a more intense nystagmus in the lean position indicates an apogeotropic form (dense particles free floating in ampullary arm or adherent to the cupula, respectively canalolithiasis or cupulolithiasis) and in this position the nystagmus direction indicates the affected side.

effective, as confirmed by a Pagnini-McClure manoeuver performed after three days. The 6 subjects affected by apogeotropic form were first subjected to the inverted Gufoni manoeuver, which transformed the apogeotropic form in the geotropic one, and then to the liberatory Gufoni manoeuver; again, a Pagnini-McClure manoeuver performed after three days confirmed the efficacy of the treatment. Table I shows the demographic data, duration of symptoms, features and SPAV of nystagmus in BLT, assumptions and treatment effectiveness. In the remaining 4/32 patients, the nystagmus direction did not change and, therefore, the NID-BLT did not offer any indication. However, the patients were further investigated, and the presence of a left, apogeotropic LSC-BPPV was hypothesised (see discussion). Statistical analysis was conducted with SPSS version 20 (IBM SPSS). The area under the ROC curve for BLT is 0.803 (p-value $<0.001$; 95\% CI $0.69-0.91)$. The test had $81.8 \%$ sensitivity and $33.3 \%$ 1-specificity (Fig. 5).

\section{Discussion}

In cases of LSC-BPPV, the BLT ("Choung's test"10) is a simple method that may help to determine the affected ear; however, it is burdened by the major limitation that it is essential to know a priori which variant (geotropic vs. 
Table I. Table I shows the demographic data, duration of symptoms, features and SPAV of nystagmus in BLT, assumptions and treatment effectiveness in 28 subjects who underwent the "NID-BLT".

\begin{tabular}{|c|c|c|c|c|c|c|c|c|c|c|}
\hline Pt. & Sex & Age & $\begin{array}{l}\text { Duration of } \\
\text { symptoms } \\
\text { in days }\end{array}$ & $\begin{array}{l}\text { Horizontal } \\
\text { nystagmus }\end{array}$ & $\begin{array}{c}\text { Bow } \\
\text { nystagmus } \\
\text { intensity and } \\
\text { direction }\end{array}$ & $\begin{array}{c}\text { Lean } \\
\text { nystagmus } \\
\text { intensity and } \\
\text { direction }\end{array}$ & Form hypothesis & $\begin{array}{l}\text { Pagnini- } \\
\text { McClure } \\
\text { manoeuver }\end{array}$ & $\begin{array}{c}\text { Inverse } \\
\text { Gufoni } \\
\text { manoeuver }\end{array}$ & $\begin{array}{l}\text { Liberatory } \\
\text { Gufoni } \\
\text { manoeuver }\end{array}$ \\
\hline 1 & $\mathrm{~F}$ & 44 & 6 & $\begin{array}{c}\text { Left } \\
\text { Pseudo-Sp }\end{array}$ & $14 \%$ sec right & $8 \% / \mathrm{sec}$ left & Right geotropic & Confirmed & Not necessary & Effective \\
\hline 2 & $\mathrm{~F}$ & 48 & 7 & $\begin{array}{c}\text { Left } \\
\text { Pseudo-Sp }\end{array}$ & $12 \%$ sec right & $6 \% /$ sec left & Right geotropic & Confirmed & Not necessary & Effective \\
\hline 3 & M & 39 & 9 & $\begin{array}{l}\text { Left After- } \\
\text { LHR }\end{array}$ & $10 \%$ sec right & $5 \% / \mathrm{sec}$ left & Right geotropic & Confirmed & Not necessary & Effective \\
\hline 4 & $\mathrm{~F}$ & 41 & 8 & $\begin{array}{c}\text { Left After- } \\
\text { BLT }\end{array}$ & $21 \% /$ sec right & $12 \%$ sec left & Right geotropic & Confirmed & Not necessary & Effective \\
\hline 5 & M & 59 & 12 & $\begin{array}{c}\text { Left } \\
\text { Pseudo-Sp }\end{array}$ & $18 \%$ sec right & $10 \%$ sec left & Right geotropic & Confirmed & Not necessary & Effective \\
\hline 6 & M & 54 & 7 & $\begin{array}{c}\text { Left } \\
\text { Pseudo-Sp }\end{array}$ & $31 \% / s e c$ right & $8 \% / \mathrm{sec}$ left & Right geotropic & Confirmed & Not necessary & Effective \\
\hline 7 & $\mathrm{~F}$ & 44 & 6 & $\begin{array}{c}\text { Left } \\
\text { Pseudo-Sp }\end{array}$ & $14^{\circ} / \mathrm{sec}$ right & $8 \% / \mathrm{sec}$ left & Right geotropic & Confirmed & Not necessary & Effective \\
\hline 8 & $\mathrm{~F}$ & 48 & 7 & $\begin{array}{c}\text { Left After- } \\
\text { BLT }\end{array}$ & $12^{\circ} /$ sec right & $6 \%$ sec left & Right geotropic & Confirmed & Not necessary & Effective \\
\hline 9 & M & 43 & 9 & $\begin{array}{c}\text { Left } \\
\text { Pseudo-Sp }\end{array}$ & $9 \% / \mathrm{sec}$ right & $3 \% / \mathrm{sec}$ left & Right geotropic & Confirmed & Not necessary & Effective \\
\hline 10 & $\mathrm{~F}$ & 41 & 8 & $\begin{array}{l}\text { Left After- } \\
\text { LHR }\end{array}$ & $21^{\circ} / \mathrm{sec}$ right & $12 \%$ sec left & Right geotropic & Confirmed & Not necessary & Effective \\
\hline 11 & M & 59 & 12 & $\begin{array}{c}\text { Left } \\
\text { Pseudo-Sp }\end{array}$ & $18 \% / s e c$ right & $10^{\circ} / \mathrm{sec}$ left & Right geotropic & Confirmed & Not necessary & Effective \\
\hline 12 & M & 54 & 7 & $\begin{array}{l}\text { Left After- } \\
\text { BLT }\end{array}$ & $31 \%$ sec right & $8 \% / \mathrm{sec}$ left & Right geotropic & Confirmed & Not necessary & Effective \\
\hline 13 & M & 43 & 13 & $\begin{array}{c}\text { Left } \\
\text { Pseudo-Sp }\end{array}$ & $12 \%$ sec right & $8 \% / \mathrm{sec}$ left & Right geotropic & Not confirmed & Not necessary & Effective \\
\hline 14 & M & 43 & 13 & $\begin{array}{c}\text { Left } \\
\text { Pseudo-Sp }\end{array}$ & $10 \%$ sec right & $8 \% / \mathrm{sec}$ left & Right geotropic & Not confirmed & Not necessary & Effective \\
\hline 15 & $\mathrm{~F}$ & 45 & 14 & $\begin{array}{c}\text { Right } \\
\text { Pseudo-Sp }\end{array}$ & $18^{\circ} / \mathrm{sec}$ left & $8 \%$ sec right & Left geotropic & Confirmed & Not necessary & Effective \\
\hline 16 & M & 48 & 10 & $\begin{array}{l}\text { Right After- } \\
\text { LHR }\end{array}$ & $14^{\circ} / \mathrm{sec}$ left & $8 \%$ sec right & Left geotropic & Confirmed & Not necessary & Effective \\
\hline 17 & $\mathrm{~F}$ & 45 & 14 & $\begin{array}{c}\text { Right } \\
\text { Pseudo-Sp }\end{array}$ & $19^{\circ} / \mathrm{sec}$ left & $6 \%$ sec right & Left geotropic & Confirmed & Not necessary & Effective \\
\hline 18 & $\mathrm{~F}$ & 45 & 14 & $\begin{array}{l}\text { Right After- } \\
\text { LHR }\end{array}$ & $18^{\circ} / \mathrm{sec}$ left & $8 \%$ sec right & Left geotropic & Confirmed & Not necessary & Effective \\
\hline 19 & M & 48 & 10 & $\begin{array}{c}\text { Right } \\
\text { Pseudo-Sp }\end{array}$ & $14^{\circ} / \mathrm{sec}$ left & $8 \% / \mathrm{sec}$ right & Left geotropic & Confirmed & Not necessary & Effective \\
\hline 20 & $\mathrm{~F}$ & 45 & 14 & $\begin{array}{l}\text { Right After- } \\
\text { LHR }\end{array}$ & $19^{\circ} / \mathrm{sec}$ left & $6 \%$ sec right & Left geotropic & Confirmed & Not necessary & Effective \\
\hline 21 & $\mathrm{~F}$ & 42 & 9 & $\begin{array}{c}\text { Right } \\
\text { Pseudo-Sp }\end{array}$ & $13^{\circ} / \mathrm{sec}$ left & $9 \% /$ sec right & Left geotropic & Not confirmed & Not necessary & Effective \\
\hline 22 & $\mathrm{~F}$ & 39 & 9 & $\begin{array}{c}\text { Right } \\
\text { Pseudo-Sp }\end{array}$ & $9 \% / \mathrm{sec}$ left & $6 \%$ sec right & Left geotropic & Not confirmed & Not necessary & Effective \\
\hline 23 & $\mathrm{~F}$ & 43 & 16 & $\begin{array}{l}\text { Right After- } \\
\text { LHR }\end{array}$ & $9 \% / \mathrm{sec}$ left & $17^{\circ} / \mathrm{sec}$ right & Right apogeotropic & Confirmed & Effective & Effective \\
\hline 24 & $\mathrm{~F}$ & 43 & 16 & $\begin{array}{c}\text { Right } \\
\text { Pseudo-Sp }\end{array}$ & $9 \% / \mathrm{sec}$ left & $14 \%$ sec right & Right apogeotropic & Confirmed & Effective & Effective \\
\hline 25 & $\mathrm{~F}$ & 51 & 17 & $\begin{array}{c}\text { Right After- } \\
\text { BLT }\end{array}$ & $7^{\circ} / \mathrm{sec}$ left & $9 \% /$ sec right & Right apogeotropic & Not confirmed & Effective & Effective \\
\hline 26 & M & 51 & 17 & $\begin{array}{c}\text { Right } \\
\text { Pseudo-Sp }\end{array}$ & $9 \% / \mathrm{sec}$ left & $11 \%$ sec right & Right apogeotropic & Not confirmed & Effective & Effective \\
\hline 27 & $\mathrm{~F}$ & 41 & 20 & $\begin{array}{c}\text { Left } \\
\text { Pseudo-Sp }\end{array}$ & $12^{\circ} / \mathrm{sec}$ right & $21^{\circ} / \mathrm{sec}$ left & Left apogeotropic & Confirmed & Effective & Effective \\
\hline 28 & M & 41 & 20 & $\begin{array}{c}\text { Left } \\
\text { Pseudo-Sp }\end{array}$ & $12^{\circ} / \mathrm{sec}$ right & $21^{\circ} / \mathrm{sec}$ left & Left apogeotropic & Confirmed & Effective & Effective \\
\hline
\end{tabular}




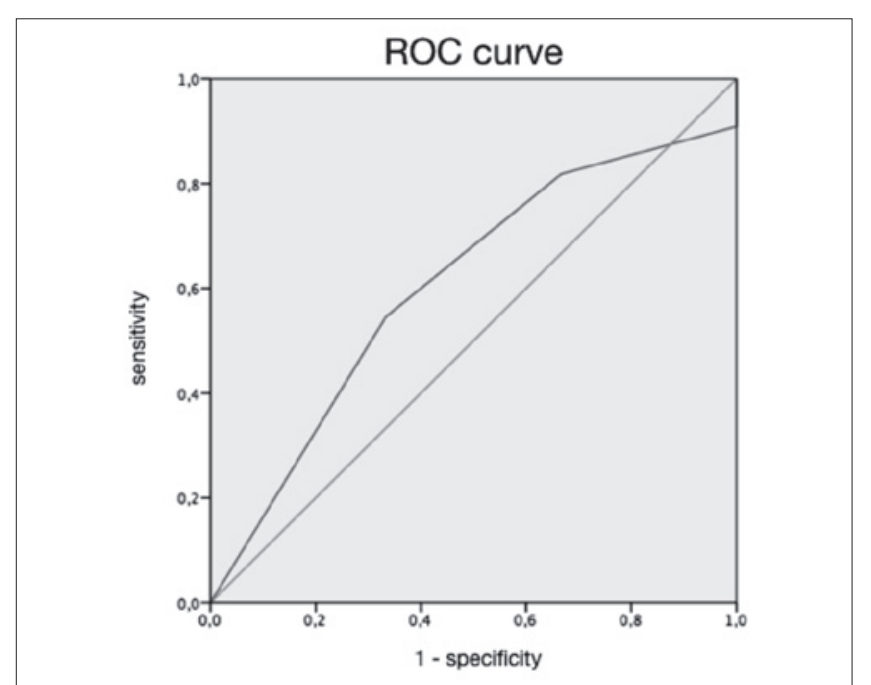

Fig. 5. ROC curve for Bow \& Lean test (BLT): the area under theta ROC curve for BLT is .803 ( $p<0.001 ; 95 \% \mathrm{Cl} 0.69$ 0.91 ). The test reported $81.8 \%$ sensitivity and $33.3 \%$ specificity. Statistical analysis was conducted with SPSS version 20 (IBM SPSS).

apogeotropic) the patient is suffering from. As reported by its authors, it is therefore essential to always integrate the BLT with the Pagnini-McClure manoeuvre.

In order to overcome this limitation, we decided to modify the BLT adding a "nystagmus intensity and direction" evaluation, which may provide information without necessarily having to resort to other tests.

As already reported, the different nystagmus intensity in the bow and in the lean position allow us to differentiate a geotropic form from an apogoetropic one, while the nystagmus direction allow us to determine the affected side. As a general rule, in both forms the direction of the more intense nystagmus points to the affected side.

The "NID-BLT" was effective in identifying the form and the side in the $79 \%$ of patients $(81.8 \%$ sensitivity and $33.3 \%$ specificity, Fig. 5).

Particularly interesting are the indications offered by the 4 subjects in which the NID-BLT did not change the nystagmus direction. In these patients, the Pagnini-McClure manoeuvre revealed a left, apogeotropic LSC-BPPV. However, the presence of a left-beating, pseudo-spontaneous nystagmus that did not reverse its direction in the two BLT positions, the null point in supine position with head rotated about $20^{\circ}$ on the left, the lack of response to the inverted Gufoni manoeuvere ${ }^{18}$ to convert the apogeotropic form into the geotropic form were all suggestive of cupulolithiasis rather than canalolithiasis. Free floating particles in the ampullary arm should in fact necessarily change their direction in both positioning and determine a change in the nystagmus direction, as well. On the contrary, it may be that particles adherent to the cupula may not be mobilised enough during the BLT as they continue to exercise a certain fixed deflection of the cupula itself, in this case of excitatory type. Otherwise, the particles would determine a different cupula deflection with the patient in the supine position, as demonstrated by the presence of the null point in supine position with head rotated about $20^{\circ}$ on the left. Therefore, this finding leads us to believe that, in the presence of LSC-BPPV, the non-reversal of the direction of horizontal nystagmus in the two positions of the BLT can be suggestive of cupulolithiasis. All patients then performed the Brandt-Daroff exercises ${ }^{20}$ and the inverted Gufoni manoeuvre converted the apogeotropic form into the geotropic form after 15 and 20 days, respectively. Subsequently, both patients were subjected to the liberatory Gufoni manoeuvre, which was immediately effective ${ }^{21}$. The effectiveness of the Brandt-Daroff exercises excludes the possibility of a light or heavy cupola ${ }^{22}$. From the above, it is evident that the most delicate phase in the execution of the NID-BLT is to distinguish the nystagmus intensity in the two different positions at the bedside, whereas no difficulties are encountered in the evaluation of the direction of the nystagmus. This represents the real limitation of our test. Failure to evaluate the different nystagmus intensity in the two different BLT positions does not allow the form to be identified correctly (geotropic vs. apogeotropic) and consequently the identification of the side: only if the form is known is it possible to identify the side.

Undoubtedly, the lack of identification of the form, and consequently of the side, in 6 of 28 patients was due to our inability to correctly identify whether the nystagmus was more intense in the bow rather than in the lean position. In particular, the video-nystagmographic recordings of these 6 patients showed an almost undetectable nystagmus and a very minimal difference between the intensities in the two positions, thus misleading us. Another limitation is the occurrence of mixed forms in which some otoconia are aderent to the cupula, but others are free-floating within the semicircular canal. Another limitation is represented by the fact that an identical flexion and extension head angle from the null point is necessary because different angles may produce different accelerations in the canal: in this case, the different nystagmus intensity may be due to ampullifugal or ampullipetal endolymph flow, but also to a slight difference in head angle.

\section{Conclusions}

Determining the affected ear in LSC-BPPV is the first and fundamental step for the diagnosis and therapy. We modified the BLT supplementing it with "nystagmus intensity and direction" bedside assessments in order to provide additional elements for diagnosis. The NID-BLT was effective in identifying the form and the correct side in 22 of 28 subjects $(79 \%)$. Because of its rapidity and ease of execution, the remarkable effectiveness in identifying form 
and affected side and despite the mentioned limitations, we believe that the bedside NID-BLT should be included routinely in the diagnostic strategy when a LSC-BPPV is suspected as a complementary test to classic manoeuvres.

\section{Acknowledgements}

The author would like to thank Elisabetta Cristiano Maria Vargas, Rino Coladangelo, Andrea Fulcheri, Antonio Giannone and Gennaro Russo for their friendship and cooperation.

\section{References}

1 McClure A. Lateral canal BPV. J Otolaryngol 1985;14:30-35.

2 Pagnini P, Nuti D, Vannucchi P. Benign paroxysmal vertigo of the horizontal canal. ORL J Otorhinolaryngol Relat Spec 1989;51:161-70.

3 Brandt T, Steddin S. Current view of the mechanism of benign paroxysmal positioning vertigo: cupulolithiasis or canalolithiasis? J Vestib Res 1993;3:373-82.

4 Brandt T. Benign paroxysmal positional vertigo. In: Brandt T, ed. Vertigo: its multisensory syndrome. $2^{\text {nd }}$ ed. Berlin: Springer-Verlag 1999, pp. 269-79.

5 Baloh RW, Jacobson KM, Honrubia V. Horizontal semicircular variant of benign positional vertigo. Neurology 1993;43:2542-9.

6 Asprella-Libonati G. Diagnostic and treatment strategy of lateral semicircular canal canalolithiasis. Acta Otorhinolaryngol Ital 2005;25:277-83.

7 Asprella-Libonati G. Pseudo-spontaneous nystagmus: a new sign to diagnose the affected side in lateral semicircular canal benign paroxysmal positional vertigo. Acta Otorhinolaryngol Ital 2008;28:73-8.

8 Bissdorff AR, Debatisse D. Localizing signs in positional vertigo due to lateral cupulolithiasis. Neurology 2001;57:1085-8.

9 Lee S-H, Choi K-D, Jeong S-H, et al. Nystagmus during neck flexion in the pitch plane in benign paroxysmal posi- tional vertigo involving the horizontal canal. J Neurol Sci 2007;256:75-80.

10 Choung Y-H, Shin YR, Kahng H, et al. "Bow and Lean Test" to determine the affected ear of horizontal canal benign paroxysmal positional vertigo. Laryngoscope 2006;116:1776-1781.

11 Nuti D, Vannucchi P, Pagnini P. Benign paroxysmal positional vertigo of the horizontal canal: a form of canalolithiasis with variable clinical features. J Vest Res 1996;6:173-184.

12 Nuti D, Vannucchi P, Pagnini P. Lateral canal BPPV: which is the affected side? Audiol Med 2005;3:16-20.

13 Han BI, Oh HJ, Kim JS. Nystagmus while recumbent in horizontal canal benign paroxysmal positional vertigo. Neurology 2006;66:706-710.

14 Koo JW, Moon IJ, Shim WS, et al. Value of lying-down nystagmus in the lateralization of horizontal semicircular canal benign paroxysmal positional vertigo. Otol Neurotol 2006;27:367-371.

15 Bisdorff AR, Debatisse D. Localizing signs in positional vertigo due to lateral cupulolithiasis. Neurology 2001;57:1085-1088.

16 Hiroaki I. Light cupula theory in persistent type of geotropic direction-changing positional nystagmus. http://homepage1. nifty.com/ichijoent/sakusaku/6_1.htm.

17 Dix MR, Hallpike CS. The pathology symptomatology and diagnosis of certain common disorders of the vestibular system. Proc R Soc Med 1952;45:341-54.

18 Gufoni M, Mastrosimone L. Trattamento con manovra di riposizionamento per la canalolitiasi orizzontale. Acta Otorhinolaryngol Ital 1998;18:363-7.

19 Marcelli V. Vestibologia clinica. Edizioni Materia Medica, 2013.

20 Brandt T, Daroff RB. Physical therapy for benign paroxysmal positional vertigo. Arch Otolaryngol 1980;106:484-5.

21 Dispenza F, De Stefano A, Costantino C, et al. Canal switch and re-entry phenomenon in benign paroxysmal positional vertigo: difference between immediate and delayed occurrence. Acta Otorhinolaryngol Ital 2015;35:116-20.

$22 \mathrm{Kim} \mathrm{CH}$, Shin JE, Kim YW. A new method for evaluating lateral semicircular cupulopathy. Laryngoscope 2015;125:1921-5.

Address for correspondence: Vincenzo Marcelli, Department of Neuroscience, Vestibular and Audiology Unit, University of Naples "Federico II", Naples, Italy. Vestibular and Audiology Unit ASL NA-1, San Giovanni Bosco Hospital, Naples, Italy. Tel. +39 081 7463496. E-mail: vimar@oneonline.it 